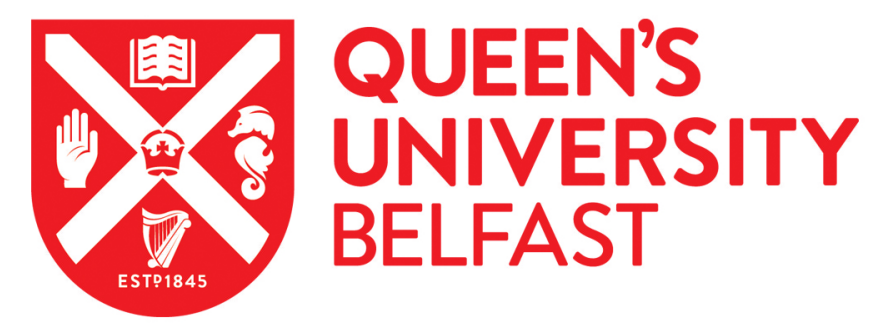

\title{
Optimised conditions for the in vitro excystment of Calicophoron daubneyi metacercariae
}

Huson, K. M., Wild, C., Fenn, C., \& Robinson, M. W. (2018). Optimised conditions for the in vitro excystment of Calicophoron daubneyi metacercariae. Parasitology, 1-5. https://doi.org/10.1017/S0031182017002220

\section{Published in:}

Parasitology

\section{Document Version:}

Peer reviewed version

Queen's University Belfast - Research Portal:

Link to publication record in Queen's University Belfast Research Portal

Publisher rights

(c) 2017 Cambridge University Press.

This work is made available online in accordance with the publisher's policies. Please refer to any applicable terms of use of the publisher.

\section{General rights}

Copyright for the publications made accessible via the Queen's University Belfast Research Portal is retained by the author(s) and / or other copyright owners and it is a condition of accessing these publications that users recognise and abide by the legal requirements associated with these rights.

Take down policy

The Research Portal is Queen's institutional repository that provides access to Queen's research output. Every effort has been made to ensure that content in the Research Portal does not infringe any person's rights, or applicable UK laws. If you discover content in the Research Portal that you believe breaches copyright or violates any law, please contact openaccess@qub.ac.uk. 
5

$6{ }^{1}$ Institute for Global Food Security, School of Biological Sciences, Queen's University Belfast,

797 Lisburn Road, Belfast, Northern Ireland; ${ }^{2}$ Ridgeway Research Ltd., Park Farm Buildings,

8 Park Lane, St. Briavels, Gloucestershire, England.

9

10 Running Title: In vitro excystment of C. daubneyi

12 Correspondence: mark.robinson@qub.ac.uk (M.W. Robinson).

13 Tel: 02890 972120; Fax: 02890975877 
17 Paramphistomosis, caused by Calicophoron daubneyi, is an emerging infection of ruminants 18 throughout Western Europe. Despite its prevalence, many questions remain regarding the basic 19 biology of this parasite and how it interacts with its host. Consequently, there is a need to 20 develop methods to study $C$. daubneyi in vitro to improve our understanding of rumen fluke biology. Towards this, we aimed to identify a suitable protocol for in vitro excystment of $C$. daubneyi metacercariae. Six methods that have been used to excyst metacercariae from a number of trematode species were tested with $C$. daubneyi metacercariae. Three of these achieved an average of $>50 \%$ excystment whilst one method, which included an acid-pepsin treatment, incubation in reducing conditions and an alkaline/bile salt solution to activate the larvae, consistently gave $>80 \%$ excystment. The latter protocol also showed no detrimental effect on the motility of newly excysted juvenile (NEJ) parasites when observed for up to 24 hours in RPMI 1640 medium post-excystment. The successful production of $C$. daubneyi NEJs in vitro is a significant step forward, and will enable the discovery of infective stage-specific parasite antigens and facilitate drug screening trials, to aid the development of much needed diagnostic and therapeutic options for paramphistomosis. 


\section{Key findings:}

- The in vitro excystment of $C$. daubneyi metacercariae has not been previously described.

- An in vitro excystment protocol for $C$. daubneyi, typically producing $>80 \%$ excystment was identified.

- This will enable the study of infective NEJs, and the development of required diagnostics/therapeutics.

\section{Introduction}

Paramphistomosis is a serious endemic infection of ruminant livestock in tropical and subtropical regions (Rojo-Vázquez et al. 2012), and in recent years it has been identified as an emerging infection in Western Europe (Huson et al. 2017). Calicophoron daubneyi has been confirmed in a number of studies as the primary rumen fluke species infecting ruminant livestock across Western Europe (Ferreras et al. 2014; Malrait et al. 2015) including the UK and Ireland (Gordon et al. 2013; Martinez-Ibeas et al. 2016; Jones et al. 2017). Morbidity and mortality attributed to paramphistome infections is invariably associated with acute disease, where ingested paramphistome metacercariae excyst in the small intestine, and the resulting NEJs cause significant damage to the intestinal tissues as they move from the small intestine lumen to the sub-mucosa (Millar et al. 2012; Pavan Kumar et al. 2016). Immature paramphistomes are thought to remain in the small intestine for up to 3 months, feeding on host tissue, before they complete their migration to the rumen where they mature and infections become patent (Sanabria and Romero, 2008).

Currently, where an active case of paramphistomosis is suspected, there is no diagnostic test available which can confirm pre-patent acute disease in an animal, therefore clinical 
paramphistomosis can only be confirmed during post-mortem examination. Mature infections may only be diagnosed by faecal egg count tests unless a post-mortem examination is performed by a veterinarian or in the abattoir. The therapeutic treatment and control of paramphistomosis at present relies on a single anthelmintic compound; oxyclozanide (Arias et al. 2013) but this is often used off-licence as it is only approved for use against fasciolid infection (asides from a single formulation of oxyclozanide to treat paramphistomosis, licensed only in France: Douvistome). Clearly, the lack of an appropriate diagnostic test and approved treatment options are not desirable in the face of this emerging parasitic infection, which has the potential to cause significant clinical disease where large numbers of metacercariae are encountered and ingested by their ruminant hosts.

In order to develop both the diagnostic tools and anthelmintic treatments for paramphistomosis, the identification of suitable diagnostic and anthelmintic targets is required. To facilitate this, researchers require access to the infective (and most pathogenic) stages, namely the $C$. daubneyi NEJs and immature small intestine-dwelling flukes. These specimens are impractical to obtain from naturally-infected animals in the abattoir, as is common for the collection of mature rumen fluke. Therefore, a reliable protocol is required to excyst $C$. daubneyi metacercariae in vitro. When successfully excysted and maintained in vitro, the resulting $C$. daubneyi NEJs will facilitate the study of infective stage-specific parasite molecules to support diagnostic development through proteomic or transcriptomic experiments (Robinson et al. 2009), as well as providing a source of infective stage parasites for in vitro studies such as the screening of existing/novel anthelmintics (Panic et al. 2013). However, anecdotal evidence from the research community suggested that $C$. daubneyi metacercariae were difficult to excyst using protocols largely developed for the liver fluke, Fasciola hepatica. Here, six previously-published methods, which had been developed for the in vitro excystment of other trematode species, were modified and tested against $C$. daubneyi metacercariae. An 
optimal protocol consistently giving $>80 \%$ parasite excystment under in vitro conditions is described.

Materials and Methods

90

91

92

\section{Parasites}

C. daubneyi metacercariae (Miskin isolate) were obtained from Ridgeway Research (Gloucestershire, UK). Metacercariae were harvested from Galba truncatula snails which had been previously infected with $C$. daubneyi miracidia. Metacercariae were washed briefly in water before use.

\section{In vitro excystment of $C$. daubneyi metacercariae}

Six methods which have been previously described for the in vitro excystment of various trematode parasite species; Fasciola hepatica (McGonigle et al. 2008), Fasciola gigantica (Nagar et al. 2010), Zygocotyle lunata (Fried et al. 1978), Paramphistomum spp (Huescaguillén et al. 2007), Acanthoparyphium spinulosum (Bass and LeFlore, 1984) and Neascus pyriformis (Schroeder et al. 1981) were selected to test with C. daubneyi metacercariae. Whilst other methods were available, the selected methods were chosen to avoid testing highly similar protocols. Some modifications, based on preliminary observations and the availability of reagents, were made to the published methods. These are detailed in Table 1. All excystment experiments performed here included incubations at $39^{\circ} \mathrm{C}$ (the approximate body temperature of the major definitive hosts of $C$. daubneyi, namely cattle, sheep and goats) with gentle agitation at $60 \mathrm{rpm}$ in a shaking incubator. 
With the exception of method 1 (incubation in $0.5 \%$ sodium hypochlorite) all groups of metacercariae were incubated at $39^{\circ} \mathrm{C}$ in $\mathrm{dH}_{2} \mathrm{O}$ for 10 mins then washed twice in $\mathrm{dH}_{2} \mathrm{O}$ with a $2 \mathrm{~min}, 500 \mathrm{x}$ g centrifugation applied between washes. Protocols were then followed as detailed in Table 2, with 2 washes in $\mathrm{dH}_{2} \mathrm{O}$ performed between all media changes, but with no centrifugation of the metacercariae after incubation in the activation media. Excystment of NEJs was monitored after 2, 4 and 6 hours incubation in the excystment media and after an overnight incubation (Fig. 2). Where the excystment protocol called for a salt solution to be used, Locke's solution (LS) $\left(0.9 \% \mathrm{NaCl}, 0.042 \% \mathrm{KCl}, 0.02 \% \mathrm{NaHCO}_{3}, 0.024 \% \mathrm{CaCl}_{2}\right)$ at $\mathrm{pH}$ 7.4 was used in all cases.

Excysted NEJs were collected from the respective excystment media by pipette under a dissecting microscope, and transferred to a $2 \mathrm{ml}$ microcentrifuge tube containing $1 \mathrm{ml}$ of warm $\left(39{ }^{\circ} \mathrm{C}\right)$ RPMI 1640 culture media, supplemented with $100 \mathrm{IU} / \mathrm{ml}$ penicillin and $100 \mathrm{mg} / \mathrm{ml}$ streptomycin. One change of the RPMI 1640 media was performed after collection of the last were purchased from Sigma-Aldrich unless otherwise stated.

\section{Results}

Three of the six methods tested (methods 4, 5 and 6) showed no or minimal parasite excystment and were not carried forward for further trials. The remaining three methods were tested in triplicate with 20 metacercariae/treatment, with an average excystment rate of 11/20 (53\%) for 
method 1, 14/20 (70\%) for method 2 and 18/20 (90\%) for method 3, respectively. These excystment levels were compared using a one-way ANOVA with Tukey's pairwise comparison using PAST (Hammer et al. 2001) and the level of excystment seen for method 3 was shown to be significantly higher than the excystment achieved with both method $1(p<0.01)$ and method $2(\mathrm{p}<0.05)$, as detailed in Fig. 1. To obtain optimal levels of excystment of metacercariae it was necessary to incubate the activated metacercariae overnight and collect NEJ parasites the following day after approximately 20 hours incubation in excystment media (Fig. 2).

It was observed that excystment of $C$. daubneyi NEJs occurred after much activity of the parasite within the cyst, with an aperture appearing at a single point in the cyst wall through which the NEJ could escape, as shown in Fig. 3. Following excystment, NEJs were successfully maintained for 24 hours in RPMI1640 medium supplemented with $100 \mathrm{IU} / \mathrm{ml}$ penicillin and $100 \mathrm{mg} / \mathrm{ml}$ streptomycin, and showed constant movement when observed.

Method 3, modified from the protocol described by Fried et al. (1978) for excystment of Zygocotyle lunata, was the most successful. This protocol was further tested with groups of 100, 500 and 1,000 metacercariae. Here the alkaline excystment medium was filter sterilised $(0.22 \mu \mathrm{m}$, Millipore Ltd, Hertfordshire, UK) before the addition of $100 \mathrm{IU} / \mathrm{ml}$ penicillin, 100 $\mu \mathrm{g} / \mathrm{ml}$ streptomycin, and $2 \mu \mathrm{g} / \mathrm{ml}$ amphotericin B to remove any undissolved bile salts and possible microbial contaminants. These further excystment trials demonstrated that the protocol is still highly successful when applied to larger numbers of metacercariae. These tests yielded $84 \%, 86 \%$ and $80 \%$ excystment rates, respectively. By the time the final 1000 metacercariae excystment test was performed, metacercariae had been stored post harvesting for up to 10 weeks at $4{ }^{\circ} \mathrm{C}$, and $>80 \%$ excystment of active, viable NEJs was still observed. 
157

Paramphistomosis, caused by C. daubneyi, is on the increase throughout Europe and is thought to be more prevalent than the liver fluke, F. hepatica, in some parts of the UK and Ireland (Toolan et al. 2015; Jones et al. 2017). Whilst the impact of chronic rumen fluke infection on animal health and production remains largely unknown, clinical disease and mortality linked to significant immature parasite burdens in the small intestine, although rare, have been reported in both sheep and cattle (Foster et al. 2008; Mason et al. 2012; Millar et al. 2012). To begin to understand how NEJ and immature C. daubneyi parasites contribute to the pathology of infected animals, and to aid the development of diagnostic tools and treatment options, we must first be able to study these life cycle stages in vitro. Towards this goal, we describe for the first time a successful method for the in vitro excystment of $C$. daubneyi metacercariae.

Previously, treatments including exposure to $\mathrm{CO}_{2}$ (Dixon, 1966), reducing conditions (Bass and LeFlore, 1984), acid-pepsin treatment and the presence of both bile salts and trypsin (Fried et al. 1978) have all been suggested to be necessary for the in vitro excystment of trematode parasites. Here, the two protocols which included a 15 min acid-pepsin treatment (methods 2 and 3) produced the highest levels of excystment, although this step does not appear to be an absolute requirement for the emergence of NEJs given the 54\% average excystment seen in method 1 where no acid-pepsin treatment was included. Furthermore, no excystment was seen with method 5 which included an hour long acid-pepsin treatment, perhaps indicating that prolonged exposure to such conditions may be detrimental to the excystment process. Greater levels of excystment were also seen with the two protocols that included a sodium dithionite treatment (methods 2 and 3), whereas a lower average excystment was seen in method 1 where L-cysteine was used to create reducing conditions. The removal of the $1 \%$ trypsin from the alkaline/bile salt medium in method 4 was necessary as during initial trials it was seen that, although up to $90 \%$ excystment was achieved, the NEJs that emerged were 
rapidly digested by the trypsin. Hence, it is possible that the trypsin used in the previously described protocol from which method 4 was adapted, and other protocols where trypsin has been included at a similar concentration (LeFlore and Bass, 1983), was only minimally active when included at $1 \% \mathrm{w} / \mathrm{v}$. Li et al. (2004) also included trypsin in their excystment protocol for $F$. gigantica, but at a much lower final concentration of $0.01 \%$. The percentage trypsin used by Li et al. (2004) is likely much closer to the in vivo concentration of trypsin in the host intestine, with an average of $143 \mu \mathrm{g} / \mathrm{ml}$ trypsin $(=0.0143 \%)$ reported in human intestinal fluid (Metheny et al., 1997). Our results, however, indicate that the presence of trypsin is not required for the in vitro excystment of $C$. daubneyi metacercariae given the success of methods 1-3 which all lacked this supplement.

For all treatment groups in which NEJs successfully emerged, whilst a considerable number of NEJs appeared after 6 hours incubation in excystment media, maximal excystment was achieved following prolonged incubation, typically overnight (up to 20 hours). This is similar to the excystment time required by Nagar et al. (2010) to obtain the maximum number of F. gigantica NEJs. Although shorter incubation times have been reported to achieve excystment in other trematode species, the success of the overnight incubation period, with no impact on the motility of the NEJs recovered after this time, makes this an efficient and convenient protocol for excystment of $C$. daubneyi metacercariae in vitro. It has recently been shown that $F$. hepatica NEJs can be excysted and maintained in vitro for long-term studies of their growth and development (McCusker et al., 2016). Our development of a successful method for in vitro excystment of $C$. daubneyi metacercariae now allows similar refinement of culture conditions that permit long-term studies of rumen fluke.

The development of the current method for the excystment of $C$. daubneyi metacercariae opens the door for a wide range of in vitro experiments using the infective stage of this emerging parasite. One research priority is the study of transcriptome and proteome 
profiles relating specifically to this infective stage (Huson et al. 2017). This would not only

207 inform our knowledge of how these parasites establish and maintain infections in the definitive

208 ruminant host but would also facilitate the discovery of potential diagnostic antigens and

209 vaccine candidates. In addition, the successful development of a method to produce $C$.

210 daubneyi NEJs paves the way for further in vitro studies to improve our understanding of the

211 developmental and molecular biology of these parasites, along with the development of in vitro

212 culture tools for drug susceptibility studies.

213

\section{Financial support}

215 This work was supported by the Biotechnology and Biological Sciences Research Council

216 (M.W.R. grant number BB/N017757/1), Agrisearch and AHDB Beef \& Lamb. 


\section{References}

Arias, M. S. S., Sanchís, J., Francisco, I., Francisco, R., Piñeiro, P., Cazapal-Monteiro, C., Cortiñas, F. J. J., Suárez, J. L. L., Sánchez-Andrade, R., Paz-Silva, a., Sanchis, J., Francisco, I., Francisco, R., Pineiro, P., Cazapal-Monteiro, C., Cortinas, F. J., Suarez, J. L., Sanchez-Andrade, R. and Paz-Silva, a. (2013). The efficacy of four anthelmintics against Calicophoron daubneyi in naturally infected dairy cattle. Veterinary Parasitology 197, 126-129. doi:10.1016/j.vetpar.2013.06.011.

Bass, H. S. and LeFlore, W. B. (1984). In vitro excystment of the metacercaria of Acanthoparyphium spinulosum (Trematoda: Echinostomatidae). Proceedings of the Helminthological Society of Washington 51, 149-153.

Dixon, K. E. (1966). The physiology of excystment of the metacercaria of Fasciola hepatica L. Parasitology 56, 431. doi:10.1017/S0031182000068931.

Ferreras, M. C., González-Lanza, C., Pérez, V., Fuertes, M., Benavides, J., Mezo, M., González-Warleta, M., Giráldez, J., Martínez-Ibeas, A. M., Delgado, L., Fernández, M. and Manga-González, M. Y. (2014). Calicophoron daubneyi (Paramphistomidae) in slaughtered cattle in Castilla y León (Spain). Veterinary Parasitology 199, 268-271. doi:10.1016/j.vetpar.2013.10.019.

Foster, A. P., Otter, A., O’Sullivan, T., Cranwell, M. P., Twomey, D. F., Millar, M. F. and Taylor, M. A. (2008). Rumen fluke (paramphistomosis) in British cattle. Veterinary Record 162, 528-528. doi:10.1136/vr.162.16.528-a.

Fried, B., Robbins, S. H. and Nelson, P. D. (1978). In vivo and in vitro excystation of Zygocotyle lunata (Trematoda) metacercariae and histochemical observations on the cyst. The Journal of parasitology 64, 395-397. 
Gordon, D. K., Roberts, L. C. P., Lean, N., Zadoks, R. N., Sargison, N. D. and Skuce, P. J. (2013). Identification of the rumen fluke, Calicophoron daubneyi, in GB livestock: Possible implications for liver fluke diagnosis. Veterinary Parasitology 195, 65-71. doi:10.1016/j.vetpar.2013.01.014.

Hammer, Ø., Harper, D. A. T. a. T. and Ryan, P. D. (2001). PAST: Paleontological Statistics Software Package for Education and Data Analysis. Palaeontologia Electronica 4(1), 1-9. doi:10.1016/j.bcp.2008.05.025.

Huesca-guillén, A., Ibarra-Velarde, F. and Sánchez-González, M. G. (2007). Paramphistomum spp: improved artificial excystment and in vitro culture of immature and adult stages. Parasitology Research 102, 41-45. doi:10.1007/s00436-007-0719-0.

Huson, K. M., Oliver, N. A. M. and Robinson, M. W. (2017). Paramphistomosis of Ruminants: An Emerging Parasitic Disease in Europe. Trends in Parasitology xx, 1-9. doi:10.1016/j.pt.2017.07.002.

Jones, R. A., Brophy, P. M., Mitchell, E. S. and Williams, H. W. (2017). Rumen fluke (Calicophoron daubneyi) on Welsh farms: prevalence, risk factors and observations on co-infection with Fasciola hepatica. Parasitology 144, 237-247. doi:10.1017/S0031182016001797.

LeFlore, W. B. and Bass, H. S. (1983). In vitro Excystment of the Metacercariae of Cloacitrema michiganensis (Trematoda: Philophthalmidae). The Journal of Parasitology 69, 200-204. doi:10.2307/3281299.

Li, S., Chung, Y. B., Chung, B. S., Choi, M. H., Yu, J. T. and Hong, S. T. (2004). The involvement of the cysteine proteases of Clonorchis sinensis metacercariae in excystment. Parasitology Research 93, 36-40. doi:10.1007/s00436-004-1097-5. 
Malrait, K., Verschave, S., Skuce, P., Van Loo, H., Vercruysse, J. and Charlier, J. (2015). Novel insights into the pathogenic importance, diagnosis and treatment of the rumen fluke (Calicophoron daubneyi) in cattle. Veterinary Parasitology 207, 134-139. doi:10.1016/j.vetpar.2014.10.033.

Martinez-Ibeas, A. M., Munita, M. P., Lawlor, K., Sekiya, M., Mulcahy, G. and Sayers, R. (2016). Rumen fluke in Irish sheep: prevalence, risk factors and molecular identification of two paramphistome species. BMC Veterinary Research 12, 1-11. doi:10.1186/s12917-016-0770-0.

Mason, C., Stevenson, H., Cox, A. and Dick, I. (2012). Disease associated with immature paramphistome infection in sheep. Veterinary Record 170, 343-344. doi:10.1136/vr.e2368.

McCusker, P., McVeigh, P., Rathinasamy, V., Toet, H., McCammick, E., O’Connor, A., Marks, N. J., Mousley, A., Brennan, G. P., Halton, D. W., Spithill, T. W. and Maule, A. G. (2016). Stimulating Neoblast-Like Cell Proliferation in Juvenile Fasciola hepatica Supports Growth and Progression towards the Adult Phenotype In Vitro. PLoS Neglected Tropical Diseases 10, 1-26. doi:10.1371/journal.pntd.0004994.

McGonigle, L., Mousley, A., Marks, N. J., Brennan, G. P., Dalton, J. P., Spithill, T. W., Day, T. A. and Maule, A. G. (2008). The silencing of cysteine proteases in Fasciola hepatica newly excysted juveniles using RNA interference reduces gut penetration. International Journal for Parasitology 38, 149-155. doi:10.1016/j.ijpara.2007.10.007.

Metheny, N. A., Stewart, B. J., Smith, L., Yan, H., Diebold, M. and Clouse, R. E. (1997). pH and Concentrations of Pepsin and Trypsin in Feeding Tube Aspirates as Predictors of Tube Placement. Journal of Parenteral and Enteral Nutrition 21, 279-285. doi:10.1177/0148607197021005279. 
Millar, M., Colloff, A. and Scholes, S. (2012). Disease associated with immature paramphistome infection. Veterinary Record 171, 509-510. doi:doi: 10.1136/vr.e7738.

Nagar, G., Raina, O. K., Varghese, A., Kumar, N., Samanta, S., Prasad, A., Gupta, S. C., Banerjee, P. S., Singh, B. P., Rao, J. R., Tewari, A. K., Paul, S., Jayraw, A. K., Chandra, D. and Garg, R. (2010). In vitro excystment of Fasciola gigantica metacercariae. Journal of Veterinary Parasitology 24, 169-171.

Panic, G., Ingram, K. and Keiser, J. (2013). Development of an in vitro drug sensitivity assay based on newly excysted larvae of Echinostoma caproni. Parasites \& vectors $\mathbf{6}$, 237. doi:10.1186/1756-3305-6-42.

Pavan Kumar, C., Syaama Sundar, N. and Devi Prasad, V. (2016). Outbreak of immature paramphistomosis in Nellore Jodipi sheep. Journal of Parasitic Diseases 40, 533-535. doi:10.1007/s12639-014-0541-4.

Robinson, M. W., Menon, R., Donnelly, S. M., Dalton, J. P. and Ranganathan, S. (2009). An Integrated Transcriptomics and Proteomics Analysis of the Secretome of the Helminth Pathogen Fasciola hepatica: proteins associated with invasion and infection of the mammalian hos. Molecular \& Cellular Proteomics 8, 1891-1907. doi:10.1074/mcp.M900045-MCP200.

Rojo-Vázquez, F. A., Meana, A., Valcárcel, F. and Martínez-Valladares, M. (2012). Update on trematode infections in sheep. Veterinary Parasitology 189, 15-38. doi:10.1016/j.vetpar.2012.03.029.

Sanabria, R. E. F. and Romero, J. R. (2008). Review and update of paramphistomosis. Helminthologia 45, 64-68. doi:10.2478/s11687-008-0012-5.

Schroeder, D. J., Johnson, A. D. and Mohammad, K. H. (1981). In Vitro Excystment of 
the Black Spot Trematode Neascus pyriformis Chandler, 1951 (Trematoda:

Diplostomatidae). Proc. Helm. Soc. Wash. 48, 184-189.

Toolan, D. P., Mitchell, G., Searle, K., Sheehan, M., Skuce, P. J. and Zadoks, R. N. (2015). Bovine and ovine rumen fluke in Ireland - Prevalence, risk factors and species identity based on passive veterinary surveillance and abattoir findings. Veterinary Parasitology 212, 168-174. doi:https://doi.org/10.1016/j.vetpar.2015.07.040. 
Table 1: Details of any modifications made to the original excystment methods tested against C. daubneyi metacercariae. ${ }^{1}$ Trematode species the excystment protocol was originally designed for.

\begin{tabular}{|c|c|c|c|}
\hline Method & Species $^{1}$ & Notes/modification of the original method & Reference \\
\hline $\mathbf{1}$ & Fasciola hepatica & $500 \mathrm{x}$ g centrifugation used during sodium hypochlorite wash step. & $\begin{array}{l}\text { McGonigle } \\
\text { et al. } \\
\text { (2008) }\end{array}$ \\
\hline 2 & Fasciola gigantica & $\begin{array}{l}1 \% \text { acidified pepsin pre-treatment included as for method } 4 \text {. Taurocholic acid } \\
\text { excluded from second incubation stage, and } 10 \%(\mathrm{v} / \mathrm{v}) \text { bovine bile was } \\
\text { included in the final RPMI } 1640 \text { incubation instead. }\end{array}$ & $\begin{array}{l}\text { Nagar et al. } \\
(2010)\end{array}$ \\
\hline 3 & Zygocotyle lunata & $\begin{array}{l}\text { After an initial test (data not shown) trypsin was removed from the original } \\
\text { protocol as NEJs were killed and digested soon after excystment, although } \\
90 \% \text { excystment was seen. Locke's solution used in place of Earle's Balanced } \\
\text { salt solution in final excystment media. Sodium tauroglucocholate used in } \\
\text { place of sodium glycocholate. }\end{array}$ & $\begin{array}{l}\text { Fried et al. } \\
\text { (1978) }\end{array}$ \\
\hline 4 & $\begin{array}{l}\text { Paramphistomum } \\
\text { spp }\end{array}$ & $\begin{array}{l}\mathrm{CO}_{2} \text { bubbling step replaced and } \mathrm{CO}_{2} \text { generated in solution by placing } \\
\text { metacercariae in } 5 \mathrm{ml} 0.45 \% \mathrm{NaCl}, 0.6 \% \mathrm{NaHCO} 3,0.15 \mathrm{M} \text { sodium dithionite } \\
\text { with the addition of } 20 \mu \mathrm{l} \text { conc. }(37 \%) \mathrm{HCL} \text { immediately before sealing and } \\
\text { incubating tubes. }\end{array}$ & $\begin{array}{l}\text { Huesca- } \\
\text { guillén and } \\
\text { Ibarra- } \\
\text { velarde, } \\
\text { (2007) }\end{array}$ \\
\hline 5 & $\begin{array}{l}\text { Acanthoparyphium } \\
\text { spinulosum }\end{array}$ & $\begin{array}{l}\text { Locke's solution used in place of Hank's balanced salt solution in initial } 1 \% \\
\text { acidified pepsin treatment. Sodium tauroglycocholate used in place of sodium } \\
\text { taurocholate. }\end{array}$ & $\begin{array}{l}\text { Bass and } \\
\text { LeFlore, } \\
\text { (1984) }\end{array}$ \\
\hline 6 & $\begin{array}{l}\text { Neascus } \\
\text { pyriformis }\end{array}$ & $\begin{array}{l}\text { Only the described optimised protocol was tested. Sodium tauroglycocholate } \\
\text { was used instead of sodium cholate. }\end{array}$ & $\begin{array}{l}\text { Schroeder } \\
\text { et al. } \\
\text { (1981) }\end{array}$ \\
\hline
\end{tabular}


Table 2. Details of the six in vitro excystment methods tested against $C$. daubneyi metacercariae. LS, Locke's solution.

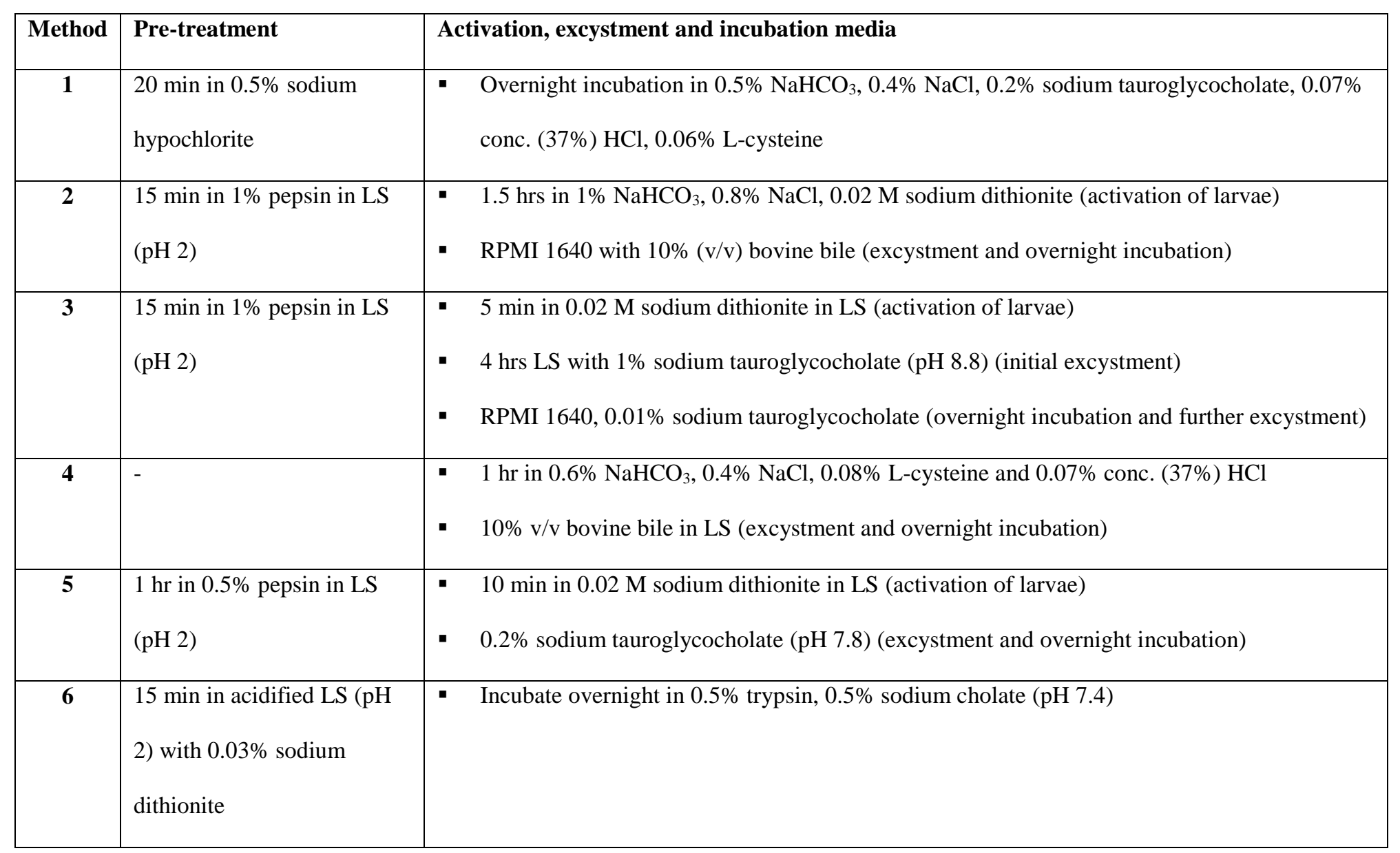


Fig. 1. Excystment rates obtained from the 3 methods which showed promising initial results ( $>50 \%$ excystment) against $C$. daubneyi metacercariae. ${ }^{* *}=\mathrm{p}<0.01, *=\mathrm{p}<0.05$.

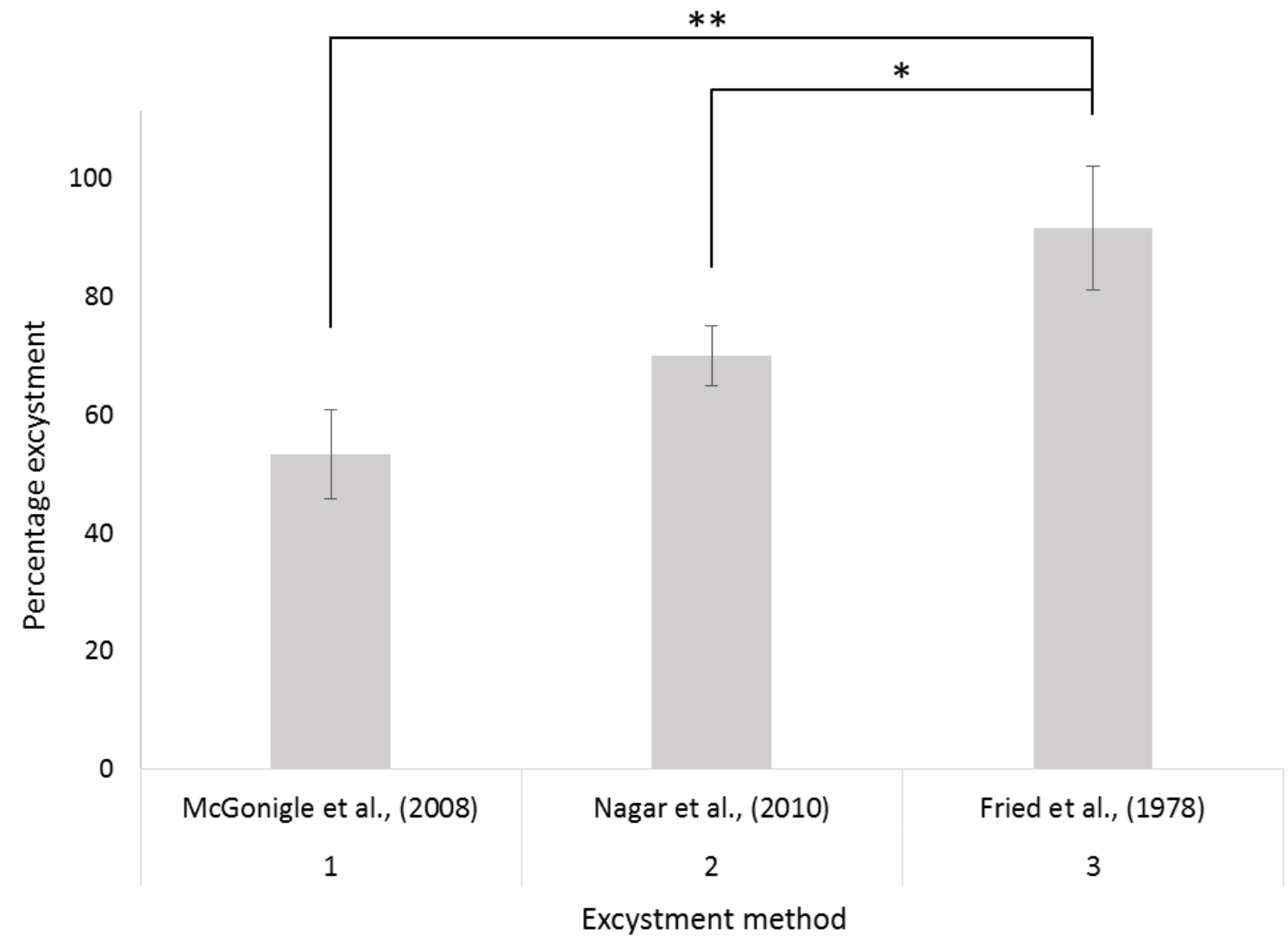


Fig. 2. Percentage excystment of $C$. daubneyi metacercariae after incubation in excystment media over a 20 hour period. Mean values are shown for those methods (1-3) which typically gave $>50 \%$ excystment.

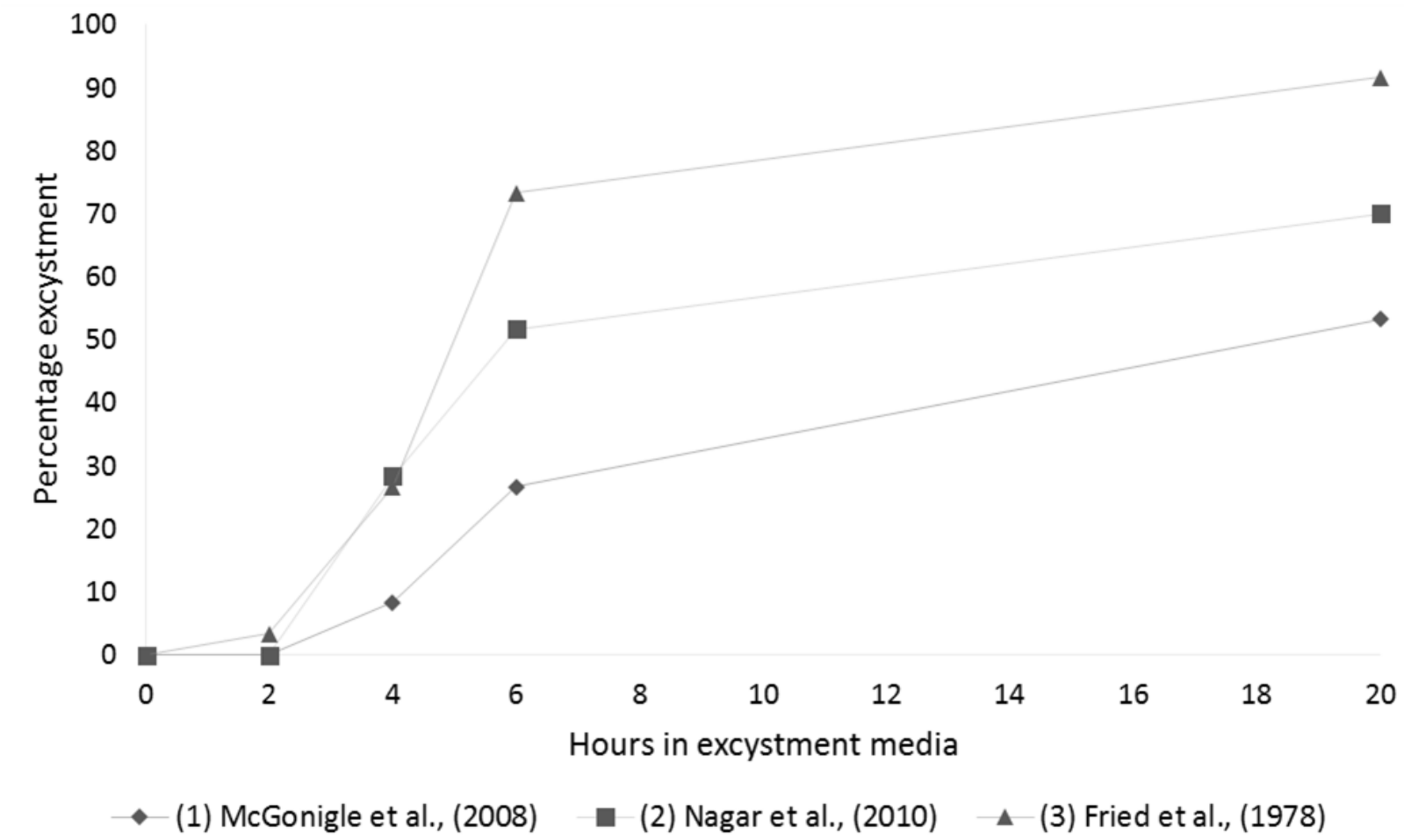


Fig. 3. Activated C. daubneyi metacercaria (pre-excystment).

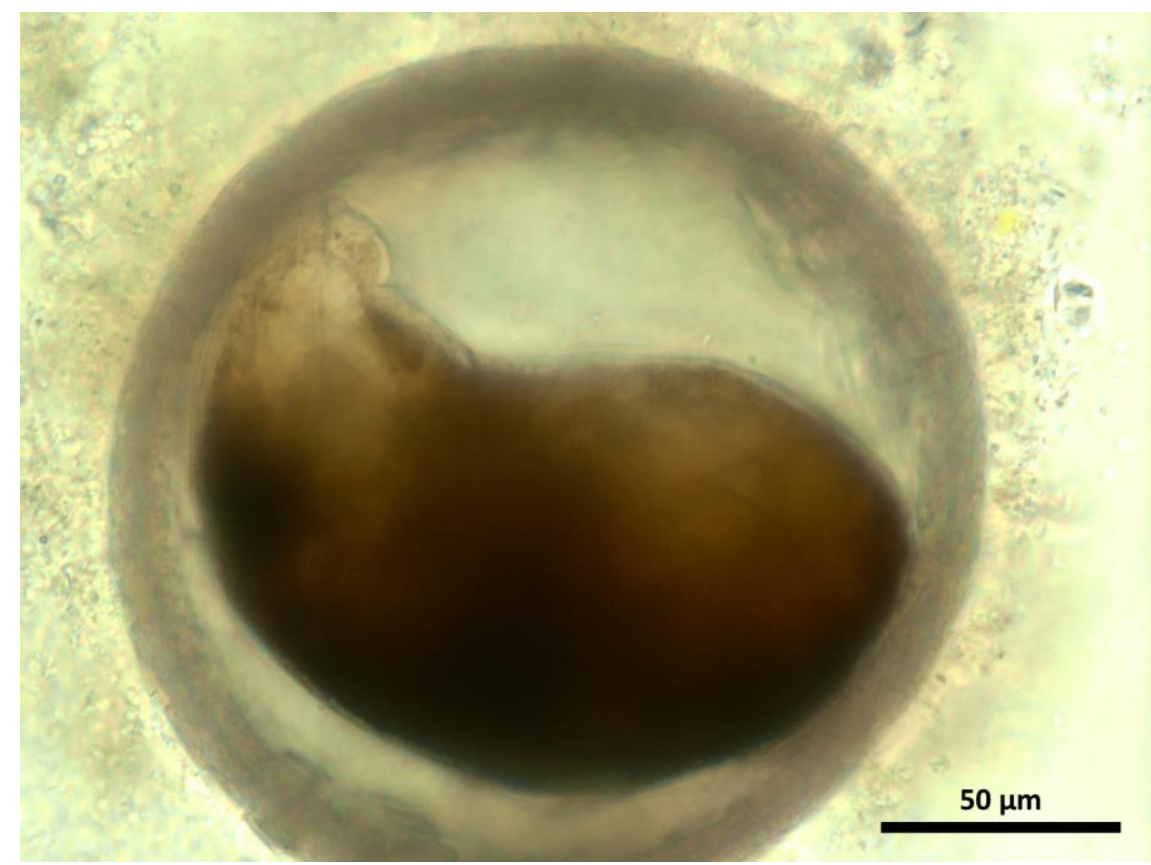

